\title{
Report from the British Paediatric Surveillance Unit
}

Introduction
The British Paediatric Surveillance Unit (BPSU) began its work in July 1986, when the first of the monthly report cards was mailed to over 800 paediatricians throughout the United Kingdom and the Republic of Ireland. Since then, the unit has been fulfilling its aim to promote awareness and increase knowledge of uncommon childhood disorders by providing an active monthly reporting scheme for paediatricians who wish to investigate particular conditions the rarity of which necessitates case recording nationally.

The effectiveness with which this aim is achieved has been measured by the following criteria: participation of respondents, quantity and quality of case reports, outcome of surveys (including new findings), interest of investigators, and dissemination of reported material.

\section{Participation of respondents}

The satisfactory performance of the BPSU is entirely dependent on the goodwill and commitment of paediatricians who spend time completing the monthly report card and subsequently in responding to requests from investigators for detailed information on the cases reported.

The average monthly response rate for 1988 was $89 \%$, ranging from $97 \%$ in East Anglia to $78 \%$ in Southern Scotland. The rates for the first and second quarters of 1989 were $88 \%$ and $89 \%$, respectively. A 'record' response was achieved in May 1989 when 757 of the 828 cards mailed $(91 \%)$ were returned. The regional variation declined in 1989 with a range during the first six months of $96 \%$ (Yorkshire) to $82 \%$ (North West Thames). As an illustration of the excellent responses to requests for further information: these were received for 103 of the total 108 initial reports of near miss drowning received in 1988 and for 117 of the 129 reports of Kawasaki disease.

\section{Outcome of surveys}

The long term nature of many of the surveys that ascertain cases of rare diseases through the BPSU precludes rapid publication, but the work of the unit is now beginning to bear fruit with several papers presented at scientific meetings, submitted for publication, or in press. ${ }^{123}$

British Paediatric Surveillance Unit S M Hall M Glickman

\section{RETROSPECTIVE SURVEYS}

Two surveys included for one mailing only, acute rheumatic fever (January 1988) and congenital rubella syndrome (April 1988), were briefly mentioned in the previous BPSU Report. ${ }^{4}$ These were pilot retrospective studies and the results are summarised here to show the problems of this approach.

A total of 20 reports of congenital rubella infection or congenital rubella syndrome among children born 1986-7 were received. Ten were already known to the National Congenital Rubella Surveillance Programme, seven had not been previously registered, and follow up was incomplete or not received for three. The National Congenital Rubella Surveillance Programme was grateful for the opportunity to increase the completeness of its case ascertainment, essential now that congenital rubella has become so rare. Because of this a new application for prospective surveillance through the BPSU from 1990 onwards was received in October 1989.

A total of 19 initial reports of acute rheumatic fever were received, for which follow up information was provided for 14 . Only nine of the patients developed their illness in 1987 (the year for which reports were requested), the other five having presented in $1984(\mathrm{n}=1), 1986$ $(n=1)$, and $1988(n=3)$. Only eight of the 14 cases met the revised Duckett-Jones criteria for acute rheumatic fever. ${ }^{5}$ A proposal for prospective surveillance throughout 1990 was received by the BPSU in 1989.

Both the congenital rubella syndrome and the acute rheumatic fever surveys illustrate the limitations of retrospective survey of rare diseases, especially those like acute rheumatic fever with a comparatively brief natural history. In addition to difficulties in obtaining follow up information and the reporting of cases outside the period of interest, there was evidence from other sources (such as hospital discharge data) that both conditions were under reported. This emphasises the value of the normal BPSU method-that is, reporting every month on cases seen during the preceding month. Not only is the memory of the case fresh in the mind of the reporting clinician, but the casenotes are readily available if more detailed information is required.

VALUE OF ACTIVE SURVEILLANCE

The advantage of 'active' over 'passive' case ascertainment for national surveillance schemes was described in the first BPSU report, referring particularly to Kawasaki disease and haemolytic uraemic syndrome ${ }^{6}$; reporting of these conditions increased sharply in mid-1986 with the change to ascertainment via the BPSU. It is especially gratifying in view of public warn- 
Follow up of cases reported: Fune 1986 to December 1989 (by Fanuary 1990)

\begin{tabular}{|c|c|c|c|c|c|c|}
\hline \multirow[t]{2}{*}{ Condition } & \multicolumn{4}{|c|}{ Confirmed reports } & \multirow{2}{*}{ 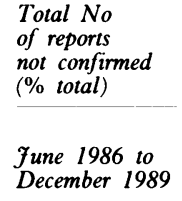 } & \multirow{2}{*}{ 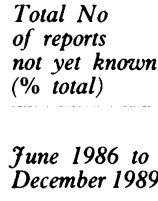 } \\
\hline & $\begin{array}{l}\text { 1986: } \\
\text { fune to } \\
\text { December }\end{array}$ & $\begin{array}{l}\text { 1987: } \\
\text { January to } \\
\text { December }\end{array}$ & $\begin{array}{l}\text { 1988: } \\
\text { January to } \\
\text { December }\end{array}$ & $\begin{array}{l}\text { 1989: } \\
\text { fanuary to } \\
\text { December }\end{array}$ & & \\
\hline AIDS in childhood* & 12 & 10 & 6 & 0 & $55(40)$ & $53(39)$ \\
\hline Neonatal herpes & 8 & 17 & 8 & 13 & $39(39)$ & $15(15)$ \\
\hline Reye's syndrome & 15 & 24 & 25 & 14 & $65(44)$ & $6(4)$ \\
\hline Kawasaki disease & 72 & 84 & 103 & 106 & $59(13)$ & $37(8)$ \\
\hline Haemolytic uraemic syndrome & 30 & 47 & 68 & 153 & $26(7)$ & 66 (17) \\
\hline Subacute sclerosing panencephalitis* & 14 & 18 & 6 & 12 & $20(24)$ & 14 (17) \\
\hline Galactosaemia & - & - & 22 & 10 & $20(31)$ & $13(20)$ \\
\hline Near miss drowning & - & - & 95 & 80 & $9(4)$ & $52(22)$ \\
\hline Haemorrhagic disease of the newborn & - & - & 13 & 6 & 27 (37) & 27 (37) \\
\hline Higher order births & - & - & - & 103 & $13(8)$ & $45(28)$ \\
\hline Congenital toxoplasmosis $\dagger$ & - & - & - & $(11) \dagger$ & $14(54)$ & $1(4)$ \\
\hline
\end{tabular}

${ }^{*}$ Reports received in 1986 include cases ever seen or seen in the past year

tReporting began in June, number includes seven cases awaiting serological follow up for final confirmation.

ings in 1986 about the use of aspirin for children that, in spite of improved reporting, annual totals of cases of Reye's syndrome dropped to 27 in 1988/9 compared with a peak of 90 in 1983/4, and were the lowest since reporting began in 1981. Through its contribution towards surveillance of conditions such as Reye's syndrome, childhood acquired immune deficiency syndrome, and-more recently-congenital toxoplasmosis, the BPSU is now providing a service that responds rapidly to public health matters in addition to its role in paediatric epidemiological research.

\section{QUANTITY AND QUALITY OF CASE REPORTS}

The cases reported from June 1986 to December 1989 are summarised in the table. Confirmed reports are those for which follow up has been obtained and which meet the case criteria. Reports 'not confirmed' include duplicates, cases reported in error, and those that do not satisfy case definitions. Reports 'not yet known' are mainly those received in the most recent months.

Diabetes stands out as the disorder for which the largest number of reports was received; the total for 1988 (1550) was substantially larger than that predicted by the investigators. The increase in haemolytic uraemic syndrome in 1988 was perhaps more apparent than real, because direct reporting by paediatric nephrologists to an independent group studying haemolytic uraemic syndrome ceased in April of that year and was replaced by reporting through the BPSU. There was, however, a marked 'real' increase in the incidence of haemolytic uraemic syndrome in 1989 compared with any previous year since 1983; it was geographically widespread and peaked over the summer months (June to October). Most patients had a bloody diarrhoeal prodrome, and Verotoxin producing Escherichia coli 0157 was isolated from some of them. This organism has now been shown to be associated with most cases of 'epidemic' haemolytic uraemic syndrome. ${ }^{7}$

Disorders with high proportions in the category 'unconfirmed' included AIDS, Reye's syndrome, haemorrhagic disease of the newborn, and congenital toxoplasmosis. For AIDS this was because respondents were invited to report children with HIV infection even if in doubt about their conformity to the strict case definition of AIDS. For Reye's syndrome many of the unconfirmed cases were children who initially met the diagnostic criteria but in whom the diagnosis was subsequently revised, most often to one of the inherited disorders of metabolism that mimic Reye's syndrome. For haemorrhagic disease of the newborn the errors were administrative: haemolytic disease was reported in the early months because the abbreviation on the report card was ambiguous; this was rectified and provided a valuable lesson on the importance of attention to detail of the design in our paperwork. 'Unconfirmed' cases of congenital toxoplasmosis included those diagnosed in previous years and infants who became seronegative on follow up. The disorders with the lowest unconfirmed rates were those with the most specific diagnostic criteria: diabetes and near miss drowning.

\section{INTEREST OF INVESTIGATORS}

Since the previous report, two studies have been completed (of haemorrhagic shock encephalopathy syndrome and childhood onset diabetes) and two others have been initiated: of congenital toxoplasmosis and higher order births. In addition to the many preliminary inquiries received by the BPSU Executive Committee, four full written proposals were received in 1989 , for surveys or surveillance of Rett's syndrome, acute rheumatic fever, congenital rubella syndrome, and severe adverse neurological reactions to measles-mumps-rubella vaccine. These disorders are to be included in 1990.

Prospective investigators should contact the BPSU office for further information and are reminded that the unit can assist not only with national, but also with regional, studies.

\section{Dissemination of reported material}

The BPSU's third annual report was produced and over 1000 copies were circulated to respondents and interested organisations in October 1989. Copies are available on request from the 
BPSU administrator, $5 \mathrm{St}$ Andrew's Place, London, NW1 4LB. Interim reports have also appeared in the Communicable Disease Report of the Public Health Laboratory Service Communicable Disease Surveillance Centre (copies available as above). Finally, with the cooperation of some of its investigators, the unit has put on two successful half day roadshows at postgraduate meetings in Bristol and Leicester.

\section{Conclusions}

In his foreward to the third annual report, Sir Cyril Clarke wrote: 'The BPSU is no longer an experiment . . . it is now an established part of paediatric epidemiology in the British Isles and is beginning to attract interest and emulation in other countries and other specialities. This review suggests that the unit is indeed fulfilling its aims.

We acknowledge the generous support of Children Nationwide which has ensured the financial stability of the unit until the end of 1992.

1 Baum JD. National survey of childhood onset diabetes, 1988. Arch Dis Child 1989;64:1221.

Ellam A, Gill N, Aids and HIV infection in the United Kingdom. Arch Dis Child 1989;64:1213.

3 Hall SM. Surveillance of Kawasaki disease in the British Isles. Arch Dis Child 1989;64:1218.

4 Hall SM, Glickman M. Report from the British Paediatric Surveillance Unit. Arch Dis Child 1989;64:439-40.

5 The American Heart Association. Jones criteria (revised) for guidance in the diagnosis of rheumatic fever. Circulation 1965;32:664

6 The British Paediatric Surveillance Unit. Arch Dis Child 1988;63:344-6.

7 Levin M, Walters MDS, Barratt TM. Haemolytic uraemic syndrome. Adv Pediatr Infect Dis 1989;4:51-82. 